\title{
A qualitative approach to organizational analysis - The applicability of qualitative studies through the Critical Incidents Technique in the implementation of organizational development programs -
}

\author{
Radu Florea \\ Antonio Amuza \\ University of Bucharest, Faculty of Sociology \\ radu.florea88@gmail.com
}

DOI:10.5901/mjss.2014.v5n22p378

Abstract

A qualitative approach in a organizationl diagnosis process has the purpose of identifying the elements that generate performance and the ones which may require improvement, and which the organization itself can control. The instruments used in qualitative studies can help to accurately point out the organizational profile by conducting interviews with key people in organizations (mainly from managerial level, and key people- specialists in certain business lines). Applying a series of techniques to describe the current situation in an organization in terms of organizational climate, culture, norms and values promoted at informal level is necessary in order to customize organizational organizational development programs on specific company needs. The CIT (Critical Incidents Technique) promotes the use of qualitative techniques in order to accurately capture specific situations (in organizational context) that may destabilize the activities of an organization. Critical incidents are understood herein as problmes/situations that require new approaches in order for them to be resolved. If an organization goes through a set of planned changes, critical incidents are seen as constructs that may be directly observed through qualitative methodology. Critical incidents can have a positive impact if they are supported by setting clear objectives and standarized actions considered in the current critical incident. Qualitative study through CIT presumes defining the specific organizational profile of a company, the type of relations that exist within it, of the behaviours, values and habbits that are promoted internaly in order to see what are the processes that are affected by organizational change. This paper is due to the empirical study of an organization which is undergoing a process of change due to the recent takeover by a foreign investment fund; the research involves identifying key points that can optimize the development program of the organization and facilitate implementation of the change process by outlining best practices applicable to the company and by poining out the common elements of the curent organizational culture and the one that is implemented.

Keywords: Organizational analysis, qualitative study, Critical Incidents Technique, Organizational Change

\section{Theoretical definition of the Critical Incidents Technique and aplicability in organizational context}

The Critical Incidents Studies cover a very wide range of fields, with applications in the field of combined structures -based on human relations- formed with the purpose of fullfiling a common goal. The critical incidents technique was developed by John Flanagan in order to see what are the aspects affecting pilots ability of learning to fly- prior explanations consisted often in ambiguous statements, without being clearly defined what are the reasons why pilots have certain behaviors (positive or negative) in learning exercises. Flanagan's technique was used to pinpoint the reasons for the pilots acting in a certain way in the learning process. According to Rogers, the essence of $\mathrm{CIT}$ is to capture „experiences of communication

", both negatively and positively charged depending on the implications they may have. (Rogers, 2005)

In organizational environments the critical incident analysis aims at identifying factors that are not part of the routine of a company, or of the standardized activities that have a range of known actions undertaken by employees. Critical incident technique requires prior analysis of the factors that are included in the conceptualization of planned change (as further development of an organization) that destabilizes the company's internal system.

Using CIT in organizational analysis implies a qualitative approach, oriented on precise measurement of behavior patterns, interests and values that may be found in an organization and the way they affect the company's well being. To analyse an organization through qualitative methodology means that the point of interest is to highlight specific issues of the company. In the study of change the relevance of a qualitative approach is given by the level of depth that the insight acquired through 
interviews may have for the change process The analysis of the current situation in an organization going through a change process involves identifying operational models considered valid by the members of the company by structuring key elements that people identify as being important for execution of organizational tasks.

Flanagan designed CIT in order to define what are the functional specifications of certain mechanisms that depend on interconnected structures - reffering to human relations-.

The term "critical" has created controversy due to its nature to emphasize the studied traits. CIT method - referenced to human behavior - states that the term "critical" defines extreme behaviors (which can be both efficient and inefficient) in atypical situations (Flanagan, 1954).

„Incidents" can make reference to actual situations that were modeled as atypical behaviors. In short, the term „critical” marks a certain behaviors intensity on a specific case, the term "incident” defining the event itself (Cope\&Watts, 2000).

Today, critical incidents can be observed in the majority of multinational organizations. The fact that in low income areas small and medium bussiness are being taken over by large corporations with similar bussiness area of interest means that changes in organizational culture, climate and strategic vision are due for. Local entrepreneurship organizations go through a process of adaptation to new work processes, different values and work procedures when they are taken over by multinational companies. Therefore, takeovers by foreign investment funds bring a natural process of organizational change. Implementation of organizational changes (defined herein as development processes) are the adaptation of employees to new work methods, different procedures and different management styles. Problems can arise often, misunderstanding due to differences between working methodologies proposed by management and the way they are perceived and accepted by member of the company. Problems of this type are due to cultural differences- this being a factor of resistance to change.

Resistances to change bring a need for accurate understanding of the current situation in which an organization is positioned in order to be surpassed. In this sense, development programs can be calibrated to the needs of employees and structures can be improved in order to function at full capacity. Applying CIT does not explain the reasons behind the existence of cultural differences but generates significant insights in order to see which elements are affected by cultural differences- the organizational context, the relationships within a company etc. (Wight, 1995). Approaching the analysis of an organization during a period of change from a qualitative perspective can improve its development by modifying (calibrating) in order to improve job satisfaction and employee performance. Qualitative techniques in organizational analysis can contribute to the definition of process maps and help optimize the defined roles in a company (Serat, 2010).

\section{CIT applicability in organizations}

CIT Analysis can be used to help companies plan, evaluate and calibrate development programs (Hetlage, 2006). For the implementation of a CIT program it is necessary to clearly define the issues that are to be investigated in order to create a valid structure for a specific case.

The use of $\mathrm{CIT}$ is aimed at pointing out practical solutions of overcoming incidents, and standardizing certain actions in organizations with the purpose of optimizing processes; CIT is implemented through 5 stages (Flanagan, 1954):

-Establish the purpose of the study

-Establish the work plan and the company's specifications

-Data collection

-Data analysis

-Data interpretation

The general purpose of the qualitative study consists in identifying the exact profile of the organization's structure, of the type of relationship that are developed in the company, the behaviors that are promoted, among with the values and habbits that are encouraged informally.

\section{Company description}

The company in which the study was conducted has a total of 165 employees, and is enlisted in the industry sector, and is in the process of developing a new product line. A qualitative approach was used to identify the firm's strenghts and needs 
for development as a result of its takeover by a foreign investement fund. The company was taken over a year ago, time in which there have been changes in operational structures, sales and support. Turnover has increased due to the financial power provided by the investment fund and the pressure on results is getting higher. With the aim to improve employee performance and create a common identity between the company and it's personnel, the company's management has started the implementation of development programs with the goal of improving individual performance of key employees and optimize working processes. These programs include phases of coaching and mentoring at management, technical trainings and programs focused on developing a common organizational culture in order to increase the overall level of satisfaction. In this respect, the study of critical incidents helps in viewing differences between the organization and employees at a value level, and help calibrating development programs in a manner consistent with the needs perceived by employees.

\section{Qualitative research methodology}

The qualitative approach used for data collection requires the use of specific tools that can define the organizational profile of the company

Table nr.1- conducting the study

\begin{tabular}{|l|l|}
\hline \multicolumn{1}{|c|}{ Activity } & $\begin{array}{l}\text { Individual interviews with company managers and } \\
\text { key specialists that have more than 1 year seniority } \\
\text { within the company }\end{array}$ \\
\hline Purpose of the activity & $\begin{array}{l}\text { To emphasize the perception that key people have } \\
\text { about the company; to identify the potential for } \\
\text { growth of the organization }\end{array}$ \\
\hline Establishing individual interviews & $\begin{array}{l}\text { Semi-structured interviews with key people in the } \\
\text { organization }\end{array}$ \\
\hline Critical Incidents & $\begin{array}{l}\text { Atypical situations that respondents face-what are } \\
\text { the factors that generate critical incidents and what } \\
\text { actions lead to resolve / standardize these situations. }\end{array}$ \\
\hline $\begin{array}{l}\text { Company-perception towards the company, and to } \\
\text { the changes that have been made; how corporate } \\
\text { values are understood by respondents. } \\
\text { Organizational climate- perception of respondents } \\
\text { about the degree in which members of the company } \\
\text { collaborate and about the general working } \\
\text { atmosphere the } \\
\text { Management- how respondents consider the } \\
\text { company is lead by managers } \\
\text { Training and career development- ways to improve } \\
\text { training processes } \\
\text { Commitment towards the company - perception of } \\
\text { commitment at company level }\end{array}$ \\
\hline
\end{tabular}


The research addresses the management team (top management and middle management of the organization), amounting to a total of 10 people that will undergo interviews based on a semi-structured interview guide to achieve the objectives of the study.

Table nr. 2- data collection

\begin{tabular}{|l|l|}
\hline Participants & The company's management team \\
\hline Data collection method & Semi-structured interview with each manager \\
\hline General aspects pursued in the interview (focus on & $\begin{array}{l}\text { Present your work in the company referring to both } \\
\text { routine matters and atypical problems? } \\
\text { Did recent changes affect your job? } \\
\text { What do you think about the way the company is } \\
\text { managed? } \\
\text { What do you thing could be improved? } \\
\text { Do you have knowledge about the company's strategic } \\
\text { objectives? } \\
\text { What suggestions do you have for improving } \\
\text { performance in the company? } \\
\text { What is your opinnion about the degree of collaboration } \\
\text { within the company? } \\
\text { How do you personally collaborate with you subordinate } \\
\text { and your colleagues from other departments? } \\
\end{array}$ \\
\hline
\end{tabular}

\section{Interpretation of the results}

As mentioned in previous chapters, the purpose of the research was to identify the key elements (both positive and negative) that define the profile of the organization in terms of its culture. Thus, as a result of the interviews we could identify that some of the most important values are Trust, Continuity, Sustainability.

Those values are well cascaded into the behaviors expected at group level, some of those being well exercised at present, others being still in need of development but having promising premises. In this respect, it is to be considered that the current organization has deep roots in the previous culture which created strong collective beliefs and habits that do not necessarily match the new ways which are endorsed by the company. The takeover of the company changed aspects regarding operational requirements and procedures and shifting the company's norms and values to a western result oriented approach. The more recent focus on a new and more complex business sector adds new challenges in this constant change process. In carrying out their activities, managers and employees with a high level of seniority in the organization compare the differences between the new vision and the one of the old company. People generally feel appreciated and well treated. However, there is a need for offering and receiving positive feedback more manifestly and consistently - for celebrating successes and for making explicit to a person that the company appreciates what he/ she does. People appreciate collective treatment and support, but feel the need for individual differentiation. As such, concerns appear related to a general feeling of inequity - „although as a team we all well treated and appreciated, individually I feel that my contribution is not enough known and appreciated."

\section{Identified Critical Incidents:}

The company's focus on sincerity - The communication within the organization is open and direct, unaffected by formalisms, hierarchical barriers or fears of punishment. However, given the previous history of the company, people still do not have the natural habit to discuss - they share ideas, give feedback and look together for solutions, but they have not developed 'real conversations' that involve getting to understand what and why the other one is thinking at a more profound level. The management team encourages those, but they still need to develop the mindset and skill for putting 
emphasis on this type of conversations and making them general practice. As opposed to the old company culture where the focus was strictly on individual performance was setting barriers in communication between departments and also between employees.

As a critical incident, the focus on sincerity has positive effects on the company- treating this as a driving factor for the development of new ways of interaction can impact the organization at all its levels.

\section{Quotes from interviews:}

„"People are beginning to understand that without open communication there can be no cooperation".

"Compared with the old company, I see that the new leadership encourages good relationships and positive climate in the workplace"

"Certainly the role of the company is to make money, and management doesn't lose sight of this. But they also visualize the mechanisms behind the turnover and profit numbers and are aware that it is important to treat others honestly and fairly. "

Lack of personal initiative for achieving performance - For the same reasons related to previous history, people maintain a concern for self-preservation. They are less inclined to take risks as not to make mistakes and lose what they have gained. They may not be always keen to propose or accept an innovative idea, or work on a new technology, so as not to fail and lose the gained statute of good expert in the eyes of the others. Peer approval seems to be very importantcomplexity and change raise some fears, as most employees have worked for years on a certain system and may feel they cannot keep up with the growing requests.

The lack of personal initiative can be enlisted as a critical incident in terms of being a behavior that blocks individual performance. There is a clear need for improvement in the majority of employees regarding initiative. Focus on inspiring self confidence can lead to successful outcomes in terms of individual performance.

\section{Quotes from interviews:}

"My people lack initiative- they do not seek solutions for problems they could handle. Maybe the last changes made them more insecure; perhaps they think they could get fired. "

"The new technology requires the use of injection; we all learn together the specifications on injection technologies; the problem is that people have emotions, not opinions, and they don't try to come up with solutions; they rather expect to come from somewhere else. In short, they are afraid to make mistakes. "

Commitment - The employees display a high level of pride to work in the company. Some of this is surely related to the low availability of work in the region, so people appreciate job security. Also, the stability gained by attaching the company to a larger organization that invests in improvement and the possibility to grow alongside a proficient organization are motivational aspects for continuing/beginning a career. People feel that they have learned and grown with the company and value their professional experience here. Also they appreciate the friendly and respectful atmosphere, giving them a high level of personal comfort and dignity in the workplace - essential in terms of organizational commitment. In this sense, commitment to the organization can be perceived as a common element between the old organizational culture and the one proposed by the new management. People trust in the changes made by the company, considering that the organization invests in them. The fact that the staff has a high commitment to the company reduces resistance to change helping to maintain a high satisfaction level and facilitating the implementation of development programs offered by the company.

As a critical incident, commitment to the company can be considered important in maintaining a high level of cohesion in the organization.

\section{Quotes from interviews:}

"After seven years of working in this company it feel like finally positive changes are made; In the last year I saw changes, and although there have been cases of people getting fired, I strongly believe that the company has invested in us as a team."

"I for one have no reason to complain. I was sent to various trainings and new procedures were created to help me understand better what I have to do; the only problem is the pressure on results, and the feeling of uncertainty. But i think that they will be resolved in a year. We just need to get used to the new rules. " 
Inequity among workers- Managers' commitment to performance also means rewarding proper behaviors, good ideas and actions as to clearly differentiate those employees from the mediocre comfortable ones, while penalizing inadequate attitudes and constantly low performance. The organization lacks active orientation towards a meritocratic culture. Faptul ca recompensele si sistemul de bonusare nu sunt suficient de clare pentru angajati constituie o problema neintalnita in vechea organizatie. The conducted interviews show that people are not satisfied of the way wages are calculated in comparisons with other colleagues. A reward system based on meritocratic criteria can help establish a profile of competence in the company and a feeling of employee identification with the company's values.

\section{Quotes from interviews:}

"People still come with complaints regarding bonuses and I keep repeating that there is nothing I can do; I wonder why there are seniority bonuses and not performance bonus among blue collar workers. That I think is a problematic situation that needs to be solved."

\section{Conclusions}

The organizational culture key elements and patterns of thinking at organizational level seem to be oriented in three directions:

Organizational commitment - The conducted interviews show that people perceive their own values as being consistent with the objectives and the values of the company. Their commitment is influenced by loyalty to the company that built their professional career, and by emotional attachment. There is a high level of enthusiasm and openness in receiving tasks and in doing all it takes to accomplish them, as workers identify themselves with their positions.

Improving outcomes - Focus on continuous improvement of processes and interest in aligning the company to the group in terms of operational practices and results. Quality is a main concern for managers and there is an expressed interest in applying the larger organizational vision for a long term perspective, as well as an intrinsic and personal drive for selfdevelopment (long-term career focus).

Developing relationships - Implementing the organizational strategy as well as the well-being of the organization is considered to depend on quality relationships between the members, both internally and in relationships with the company. People tend to place a strong focus on building and maintaining good quality relations amongst themselves and with employees, and a positive atmosphere at work, in this respect being focused rather on the collective than on the individual.

The purpose of the study was to capture the main elements of the organizational culture of the company through semistructured interviews with the purpose of identifying factors that are perceived as being positive in the organization but also the development needs that can be solved by implementing development programs.

Critical incidents - defined in this paper as atypical cases that are going through a standardization process- were used for shaping specifications of the organizational culture in order to have an accurate description of the current state of the organization.

To adress organizational analysis from a qualitative perspective defines organizational culture at a level felt by all the organization's personnel, and not only from a point in which certain aspects are only communicated throughout formal communication channels. The values of a company and the implementation of the principles that guide it are felt through the relationship that managers have with employees but also through they way that the company invests in maintaining good relations between it's representatives and it's clients.

A qualitative CIT analysis that is focused on defining organizational culture can help organizations optimize personnel turnover and achieve high performance through positive people oriented management systems.

\section{Acknowledgment}

This paper has been financially supported within the project entitled "SOCERT. Knowledge society, dynamism through research", contract number POSDRU/159/1.5/S/132406. This project is co-financed by European Social Fund through Sectoral Operational Programme for Human Resources Development 2007-2013. Investing in people! 


\section{References}

1.Flanagan J, 1954 The critical incident technique, Psychological Bulletin Vol. 51, No. 4, American Institute for Research, University of Pittsburgh

2.Fountain J, Kennedy J, 1999, A note on the Critical incident Technique and its utility as a tool of public management research, Note presented at the panel on qualitative methods, annual meeting of the Association of.Public Policy and Management, Washington, D.C., November 4-6, 1999.

3.Hettlage R., Steinlin M, 2006, The critical incident technique in knowledge Management- Related Contexts- a tool for exploration/planning/evaluation and empowerment/animation. Helvetas Swiss Association for International Cooperation

4.Hugher $\mathrm{H}, 2012$, An expanded critical incident approach for exploring information use and learning, Library and Information Research 36 (112) p. 72-95

5.Koch A, Strobel A \& Kici G, 2009, Quality of the Critical Incident Technique in practice: Interrater reliability and users' acceptatnce under real conditions, Psychology Science Quarterly, Volume 51 p 3-15

6.Mallak L, Lyth D, Olson S \& Others, 2003, Diagnosing culture in health-care organizations using critical incidents, International Journal of Health Care Quality Assurance16/4 [2003] 180-190

7.Serrat O, 2010, The Critical Incident Technique, Cornel University ILR School

8.Rous B, McCormick K, 2006, Critical Incident Technique: A valuable Research Tool for Early Intervention, NECTC, University of Kentucky

9.Woloshynowych M, Rogers S, Taylor-Adams S, Vicent M, 2005 The investigation and analysis ofcritical incidents and adverse eventsin healthcare, Health Technology Assessment 2005; Vol. 9: No. 19 